\title{
Dispersion of Titanium Oxide Nanoparticles in Aqueous Solution with Anionic Stabilizer via Ultrasonic Wave
}

\author{
Wen-Bin Tsai, ${ }^{1}$ Jui-Yang Kao, ${ }^{1}$ Tzong-Ming Wu, ${ }^{2}$ and Wen-Tung Cheng ${ }^{1}$ \\ ${ }^{1}$ Department of Chemical Engineering, National Chung Hsing University, Taichung, Taiwan \\ ${ }^{2}$ Department of Materials Science and Engineering, National Chung Hsing University, Taichung, Taiwan
}

Correspondence should be addressed to Wen-Tung Cheng; wtcheng@dragon.nchu.edu.tw

Received 23 May 2016; Revised 3 October 2016; Accepted 18 October 2016

Academic Editor: Jean-Francois Hochepied

Copyright (C) 2016 Wen-Bin Tsai et al. This is an open access article distributed under the Creative Commons Attribution License, which permits unrestricted use, distribution, and reproduction in any medium, provided the original work is properly cited.

\begin{abstract}
This paper aims to reveal the effects of odium hexametaphosphate (SHMP) and polyacrylic acid (PAA) on dispersion of $\mathrm{TiO}_{2}(\mathrm{P} 25)$ nanopowder in de-ionic water through ultrasonic horn. We characterized $\mathrm{TiO}_{2}$ suspension by transmission electron microscopy (TEM), dynamic light scattering (DLS), Fourier transform infrared spectroscopy (FTIR), zeta potential, and surface contact angle instruments. As shown in the results, particularly, it were noticed that (1) the SHMP has better dispersion than PAA due to electronegativity effect, resulting in that the average particle size of the dispersed titanium dioxide in de-ionic water was roughly $92 \mathrm{~nm}$, and (2) the zeta potential of $\mathrm{TiO}_{2}$ suspension with SHMP can be achieved by $54 \mathrm{mV}$ at $\mathrm{pH}$ value of 7.7, causing stronger electrostatic repulsion in the suspension solution, compared with PAA.
\end{abstract}

\section{Introduction}

The optimized utilization of functional particles is very important for the practical applications ranging from catalysts, polishing media, and cooling fluids to cosmetics and sunscreens, which requires robust and cost-effective dispersion and surface functionalization routes. Additionally, nanopowder dispersion for chemicals, food, medicament, paint, and construction has become an important application in various fields. Because the nanoparticle has the volume and surface effects, it has outstanding qualities on light absorption, catalysis, magnetism, and so on. However, the small size of particle is easily agglomerated and difficult to exhibit the advantages of nanoparticles. Therefore, how to improve the dispersion stability of nanoparticles in the liquid phase is a significant issue. $\mathrm{TiO}_{2}$ nanoparticles can be used for a variety of applications including self-cleaning [1], water treatment [2], antibacterial [3], and air purification [4] due to their effective photocatalytic activity. Furthermore, the $\mathrm{TiO}_{2}$-based hybrid nanomaterials [5] are one of the most common nanocomposites, which are widely applied in medicine, lithium batteries, UV-screening, sensors, and hybrid solar cell materials. For these applications, $\mathrm{TiO}_{2}$ nanoparticles are generally coated on suitable substrates. Among them, the coating process to use $\mathrm{TiO}_{2}$ suspensions by spraying is the most costeffective method. Producing $\mathrm{TiO}_{2}$ suspensions necessitates the incorporation of $\mathrm{TiO}_{2}$ nanoparticles in the liquid phase, the break-up and dispersion of nanoparticle clusters, and subsequently stabilization. However, small particles tend to agglomeration which is generally due to the van der Waals attraction forces between particles which can be counterbalanced by electrostatic and stereo stabilization [6,7], resulting in low or complete absence of chemical activity.

Generally, the combination of both electrostatic and stereo stabilization was termed as electrosteric stabilization [8], which can be achieved using polyelectrolytes. A polyelectrolyte was a polymer chain with numerous dissociable groups $[9,10]$. Many studies have focused on the dispersion stability of $\mathrm{TiO}_{2}$ particles in water [11-13]. A lot of applications of PAA were based on the use of thin films and coatings. PAA coatings and thin films were prepared by electrosynthesis $[14,15]$ from acrylic acid monomer solutions. Furthermore, Othman et al. [16] used two common dispersants which were PAA and ammonium poly-methacrylate to find that the $3 \mathrm{wt} \%$ of PAA is the optimal dispersion. Vallar et al. [17] found the optimal the dispersion parameters of the oxide slurries by zeta potential measurements. Liufu et al. [18] stated the adsorption of PAA in aqueous suspension onto the 
TABLE 1: Specification of titanium oxide used in this study.

\begin{tabular}{lcccc}
\hline Particle & Average primary size $(\mathrm{nm})$ & Density $\left(\mathrm{g} / \mathrm{cm}^{3}\right)$ & Surface area $\left(\mathrm{m}^{2} / \mathrm{g}\right)$ & Color \\
\hline $\mathrm{TiO}_{2}$ & 21 & 3.93 & $50 \pm 15$ & White \\
\hline
\end{tabular}

surface of $\mathrm{TiO}_{2}$ nanoparticles and discussed the major factors influencing the adsorption of PAA. Rana et al. [19] investigated the effects of their synthesized PAA on rheological and dispersion properties of $\mathrm{TiO}_{2}$ suspensions. Acrylic polymers because of their flexibility, good adhesion strength, drying at room temperature, preparation of glossy coatings, and good chemical resistance, as well as suitable price, have gained much interest in coating industry. On the other hand, sodium hexametaphosphate (SHMP) was widely used in industry as a preservative due to its well-established antimicrobial effects [20] and ability to disperse microbial biofilms [21, 22]. Cui et al. [23] used $\left(\mathrm{NaPO}_{3}\right)_{6}, \mathrm{Na}_{2} \mathrm{SiO}_{3}$, and $\mathrm{C}_{2} \mathrm{H}_{5} \mathrm{OH}$ to disperse for $\mathrm{TiO}_{2}$ particles in aqueous solution. The experimental result show that $\left(\mathrm{NaPO}_{3}\right)_{6}$ was efficient dispersants for $\mathrm{TiO}_{2}$ particles in aqueous solution.

Ultrasonic wave has been proven as a useful tool to disperse nanoparticles and to eliminate agglomeration in aqueous suspensions [24]. Shock waves caused by collapsing cavitation under ultrasonic irradiation will lead to collisions among particles, whereby the agglomerated particles are eroded and split apart by the collisions [24, 25]. Ghadimi and Metselaar [26] presented two ultrasonic technologies, namely, ultrasonic probe and ultrasonic bath, respectively, to combine surfactant displayed different stability and characteristic improvements. Chung et al. [27] worked on the stability of nanofluid under various ultrasonic conditions. They revealed that the particulate size of nanofluids is proportional to the volume fraction and decreased with the ultrasonic power.

In the present study, we aim to examine the effects of inorganic and organic stabilizers on dispersion of $\mathrm{TiO}_{2}$ nanopowder in de-ionic water via probe ultrasonication by using transmission electron microscopy (TEM), dynamic light scattering (DLS), Fourier transform infrared spectroscopy (FTIR), zeta potential, and surface contact angle instruments to determine the difference for $\mathrm{TiO}_{2}$ suspension with sodium hexametaphosphate (SHMP) and polyacrylic acid (PAA) stabilizers, respectively. It is expected to provide guidance to develop the $\mathrm{TiO}_{2}$ /water nanofluid with excellent performance heat exchange process.

\section{Materials and Methods}

2.1. Materials. Titanium dioxide (Degussa, P25) with an average particles size of $21 \mathrm{~nm}$ was used as a study material, which consists of more than $70 \mathrm{wt} \%$ anatase with a minor amount of rutile and a small amount of amorphous phase and its specifications are shown in Table 1 . De-ionic water $(18.1 \Omega)$ was used as the continuous phase, which has been mechanically filtered or processed to remove impurities. Sodium hexametaphosphate (99\%, SHOWA) and polyacrylic acid (99\%, Mw: 2000, ACROS) were, respectively, used as inorganic and organic stabilizers to enhance suspension stability.
2.2. Preparation of Suspension. The experiments were carried using $0.05 \mathrm{wt} \%, 0.01 \mathrm{wt} \%$, and $0.005 \mathrm{wt} \%$ of titanium dioxide mixing with $20 \mathrm{~mL}$ of de-ionic water at the temperature of $25^{\circ} \mathrm{C}$. The samples were then dispersed by an ultrasonic horn (Hoyu Ultrasonic Clash, $250 \mathrm{~W}, 23 \mathrm{kHz}$, Taiwan) in a vessel of $25 \mathrm{~mL}$ for $480 \mathrm{sec}$, which is based on obtaining smaller secondary average size of dispersed $\mathrm{TiO}_{2}$ particle, followed by adding the different amounts ( $1 \mathrm{wt} \%, 3 \mathrm{wt} \%, 5 \mathrm{wt} \%$, and $7 \mathrm{wt} \%)$ of stabilizer and stirring for $24 \mathrm{hrs}$. To keep the dispersions from overheating during sonication, the dispersions were sonicated in a cooling-water bath maintained at a constant temperature of $25^{\circ} \mathrm{C}$.

2.3. Characterization. After dispersing $\mathrm{TiO}_{2}$ capped with anionic surfactant through the ultrasonic dispersion process, the dynamic light scattering analyzer (Malvern Zetasizer Nano Series) was applied for measuring the particle size and distribution and zeta potential, where values were averaged by three times of measurement after preparing each suspension and standing for $30 \mathrm{~min}$; Fourier transform infrared spectroscopy (FTIR) (Perkin Elmer Spectrum One) was employed to examine the adsorption of stabilizer on titanium oxide particles, where samples were prepared when the dispersion solution was centrifuged for $30 \mathrm{~min}$ with angular speed of 5000 cycle $\mathrm{min}^{-1}$ and the resulted powders were eluted with distilled water and afterward dried in an oven at $100^{\circ} \mathrm{C}$ for $12 \mathrm{~h}$, followed by mixing with $\mathrm{KBr}$ by grinding to fabricate pellets; a pH meter (InLab 439/120) is an electronic device for measuring the $\mathrm{pH}$ value of dispersion solution; and the surface contact angle of dispersion liquid on the glass was analyzed by the instrument of Kruss DSA10.

\section{Results and Discussion}

3.1. Concentration of $\mathrm{TiO}_{2}$ Nanoparticles in Aqueous Solution. We prepared three concentrations (i.e., 0.005, 0.01, and $0.05 \mathrm{wt} \%$ ) of $\mathrm{TiO}_{2}$ suspensions without stabilizer to reveal the effect of amount of $\mathrm{TiO}_{2}$ on the particle size in the dispersion solution. As seen from Figure 1, after dispersing by ultrasonic horn for $480 \mathrm{sec}$, the particle size of suspension was gradually becoming small with decreasing the concentration of $\mathrm{TiO}_{2}$ in de-ionic water, where $\mathrm{pH}$ values are $5.98 \pm 0.14,5.63 \pm 0.01$, and $5.11 \pm 0.25$, respectively, for $0.005,0.01$, and $0.05 \mathrm{wt} \%$ of $\mathrm{TiO}_{2}$ suspensions in de-ionic water in the absence of stabilizer. Figure 2 is TEM images to be used for monitoring the amount of titanium oxide dependent on the aggregation of particle. As shown in the figure, it could be found that the secondary particle size is increased with increasing concentration of particle in suspension, where average particle sizes of dispersed $\mathrm{TiO}_{2}$ are ranged from $175 \mathrm{~nm}$ to $250 \mathrm{~nm}$ in de-ionic water in the absence of stabilizer. This suggests that the high power of ultrasonic horn is necessary to overcome the interparticle force for higher amount of $\mathrm{TiO}_{2}$ in de-ionic 


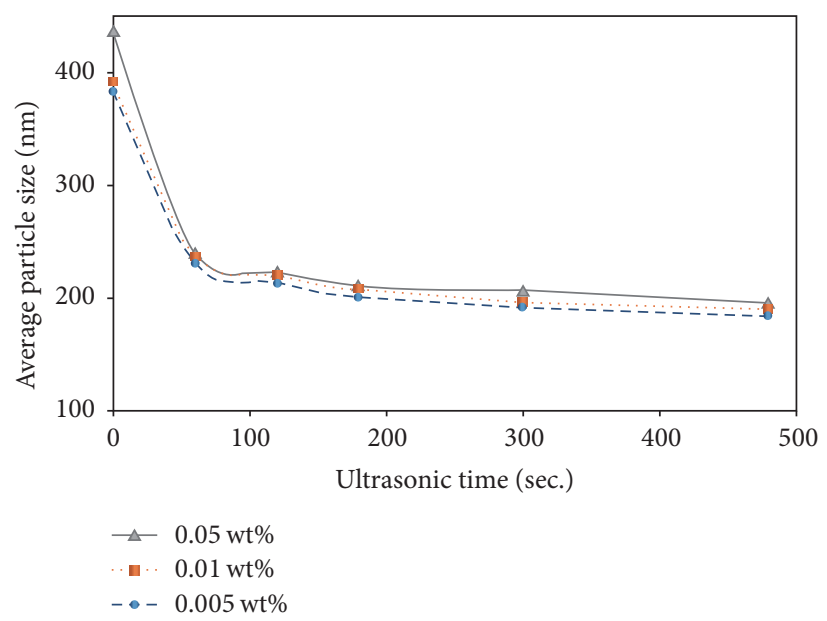

FIGURE 1: Average particle size of dispersed $\mathrm{TiO}_{2}$ without stabilizer as function of ultrasonic time for the different amount of dispersing phase.

water. In this work, the suitable concentration of $\mathrm{TiO}_{2}$ particle for nanofluid was determined by $0.005 \mathrm{wt} \%$ after dispersing through ultrasonic probe for 480 sec to obtain the smaller size of dispersed particles size in aqueous solution with stabilizer.

3.2. Surfactant Amount for Dispersing $\mathrm{TiO}_{2}$ Nanoparticles. As shown in Figure 3, it was observed for the effect of stabilizer amount on the size of dispersed $\mathrm{TiO}_{2}$ particles through the ultrasonic dispersion process. With changing the amount of SHMP and PAA stabilizers, respectively, we found that $5 \mathrm{wt} \%$ of stabilizer was an appropriate amount to disperse $\mathrm{TiO}_{2}$ in de-ionic water because the smaller average particle size could be obtained. In particular, it was shown that the average particle size of dispersed $\mathrm{TiO}_{2}$ in de-ionic water in the presence of SHMP stabilizer was about $92 \mathrm{~nm}$, which was validated by TEM image, as presented in Figure 4(a).

Figure 5 is FTIR analysis for the $\mathrm{TiO}_{2}$ particles capped without and with $5 \mathrm{wt} \%$ of PAA and SHMP stabilizers, respectively, after dispersing in DI-water via sonication. As viewed from the spectrum, SHMP and PAA stabilizers displayed a strong absorption band at $1650 \mathrm{~cm}^{-1}$ and $1250 \mathrm{~cm}^{-1}$, respectively, indicating $-\mathrm{C}=\mathrm{O}$ and $-\mathrm{P}=\mathrm{O}$ stretching vibration for carboxylic acids and phosphoric acid [28]; meanwhile, the FTIR spectrum of $\mathrm{TiO}_{2}$ particles showed intense broadband in the vicinity of 400 to $800 \mathrm{~cm}^{-1}$ [29]. These findings proved that stabilizers were adsorbed onto the surface of $\mathrm{TiO}_{2}$ particles.

3.3. Stability of $\mathrm{TiO}_{2}$ Nanosuspensions with Stabilizer. The stability of $\mathrm{TiO}_{2}$ suspension in aqueous solution is closely related to its electrokinetic properties. The well-dispersed suspension can be obtained with high surface charge density to generate strong repulsive forces [30-32]. In addition, the salts are containing the multiply charged ions such as polyphosphate, hexametaphosphate, pyrophosphate, and polysilicate anions can be alternatively applied as dispersing salt. The multiple charged ions might be adsorbed by the particle in an aqueous environment and leads to an increase in particle surface charge and zeta potential [6]. Figure 6 shows that zeta potential of $\mathrm{TiO}_{2}$ particle with stabilizer is greater than that without stabilizer, meaning that the surface charge on particle has been changed, where $\mathrm{pH}$ values of suspension were changed from 8.2 to 7.7 and 6.2, respectively, for SHMP and PAA stabilizers. In addition, it was found that the zeta potential of $\mathrm{TiO}_{2}$ suspension with SHMP is greater than that with PAA. As sketched in Figure 7, this is because SHMP have stronger polarity due to larger electron negativity [33, 34], compared to polyacrylates, producing high charge density on the surface of $\mathrm{TiO}_{2}$ particle

For further validation, surface contact angle analysis was performed by dropping the $\mathrm{TiO}_{2}$ suspension without and with stabilizers of SHMP and PAA, respectively, on glass substrate. As displayed in Figure 8, the surface contact angle of $\mathrm{TiO}_{2}$ suspension with SHMP was remarkably larger than that with PAA. It implies that the surface contact angle of $\mathrm{TiO}_{2}$ suspension with SHMP is close to that without stabilizer, meaning that the wettability of $\mathrm{TiO}_{2}$ suspension with SHMP on glass surface is similar to that without stabilizer due to higher polarity of dispersion solution resulting from the higher electronegativity of SHMP, compared to $\mathrm{TiO}_{2}$ suspension with PAA. In other words, the glass surface has affinity with the dispersion solution in the presence of PAA.

Figure 9 illustrates zeta potential of dispersed $\mathrm{TiO}_{2}$ in de-ionic water varying with the amounts of SHMP and PAA stabilizers at $\mathrm{pH}$ values of 7.7 and 6.2, respectively. As analyzed from the figure, the maximum zeta potential value of $\mathrm{TiO}_{2}$ suspension contains $5 \mathrm{wt} \%$ of SHMP and PAA stabilizers, respectively, corresponding to average particle size of dispersed $\mathrm{TiO}_{2}$ in de-ionic water as functions of amount of stabilizer, resulting from the limitation of surface area of $\mathrm{TiO}_{2}$ particle. The zeta potential value of $\mathrm{TiO}_{2}$ suspensions with and without stabilizers as functions of $\mathrm{pH}$ is shown in Figure 10. As displayed in the figure, the absolute value of zeta potential in the presence of stabilizer is higher than that in the absence of stabilizer. As $\mathrm{pH}$ increases, the zeta potential of the particle surface increases, resulting in the fact that the electrostatic repulsion force between particles is sufficient to prevent attraction and collision between particles caused by Brownian motion [35]. As indicated by the dash line in the figure, the isolated electrical points (IEP) are roughly located at $\mathrm{pH}$ values of 5.7, 3.1, and 2.9, respectively, for the $\mathrm{TiO}_{2}$ 

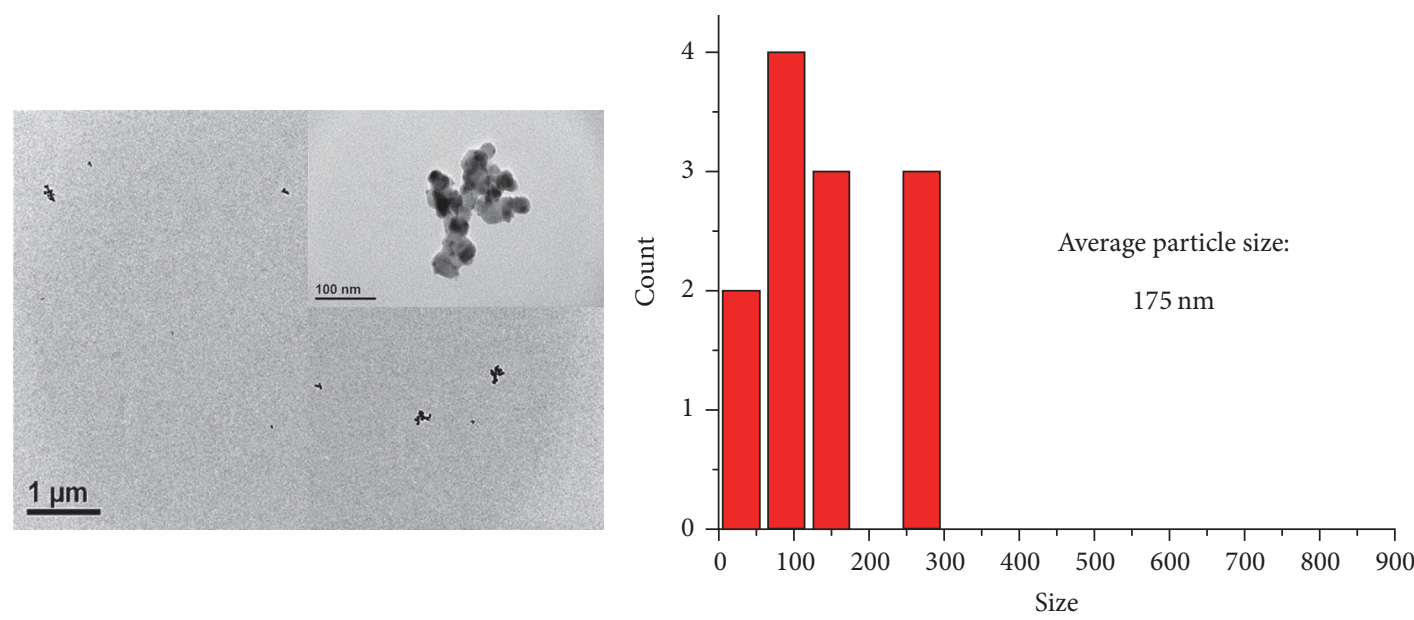

(a)
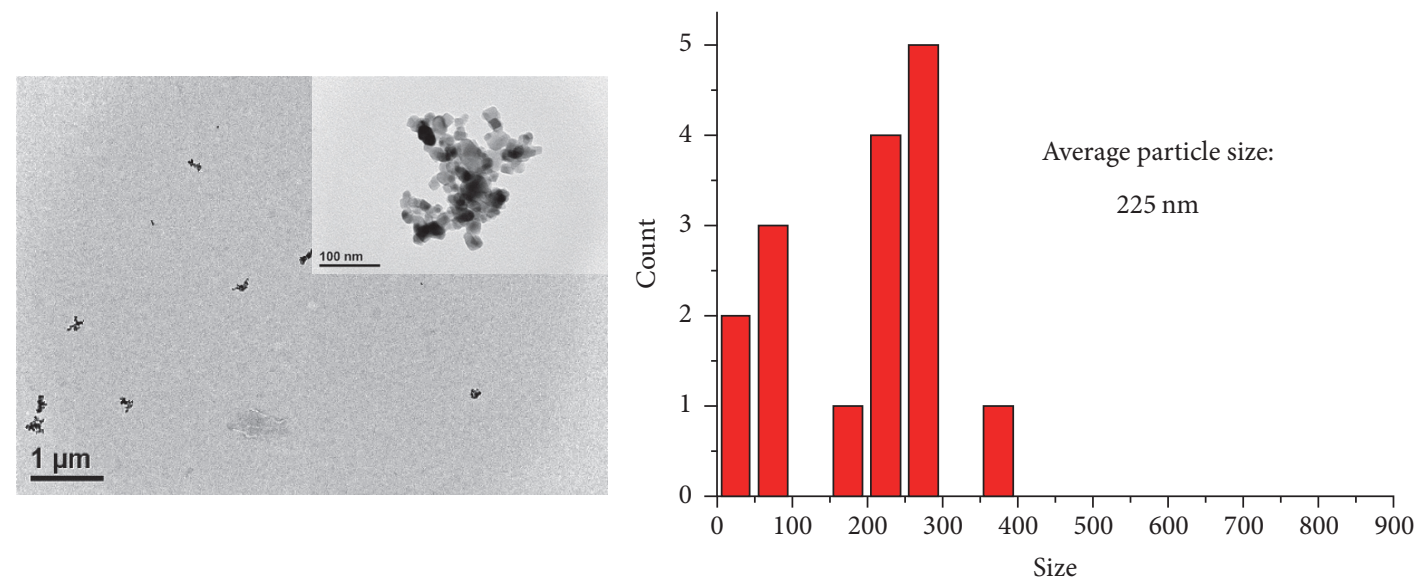

(b)
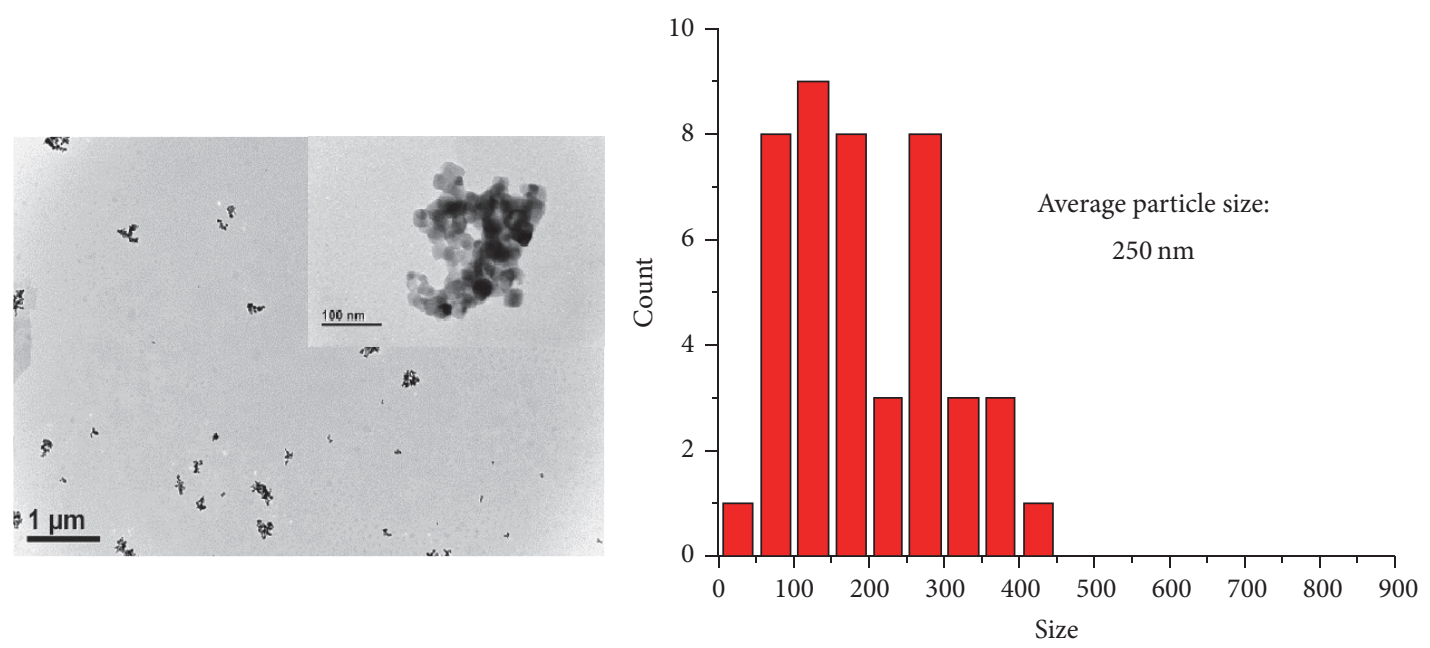

(c)

Figure 2: Particle size distribution and TEM images with scale bars of $1 \mu \mathrm{m}$ and $100 \mathrm{~nm}$ of suspension containing (a) $0.005 \mathrm{wt} \%$, (b) $0.01 \mathrm{wt} \%$, and (c) $0.05 \mathrm{wt} \%$ of $\mathrm{TiO}_{2}$ in the absence of stabilizer after dispersing by ultrasonic probe for $480 \mathrm{sec}$. 


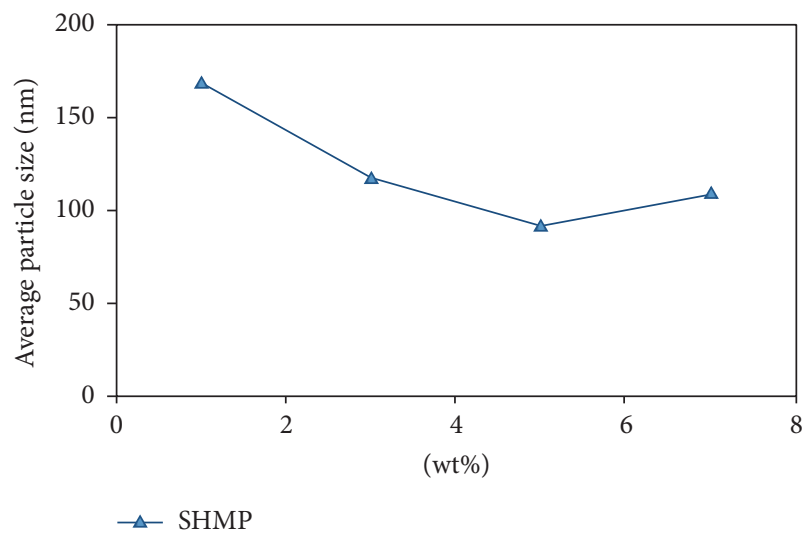

(a)

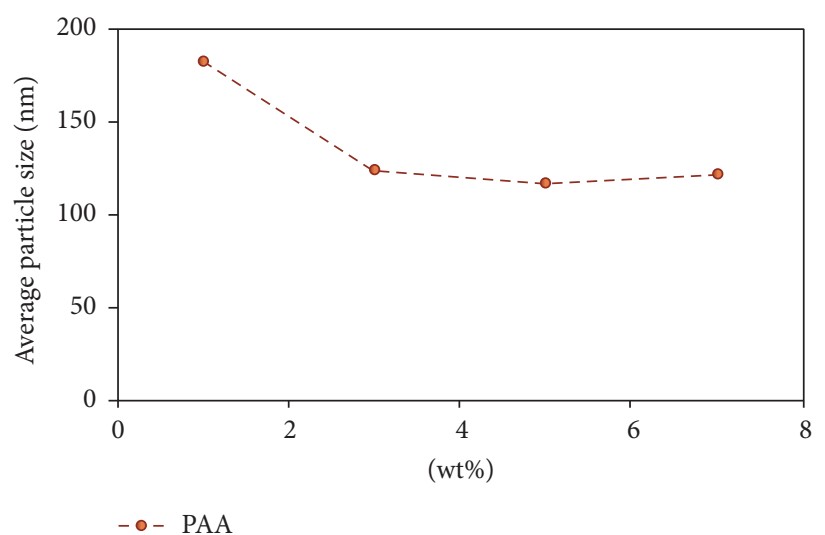

(b)

FIGURE 3: Average particle size of dispersed $\mathrm{TiO}_{2}$ in aqueous solution varying with the amount of (a) SHMP and (b) PAA stabilizers, respectively.

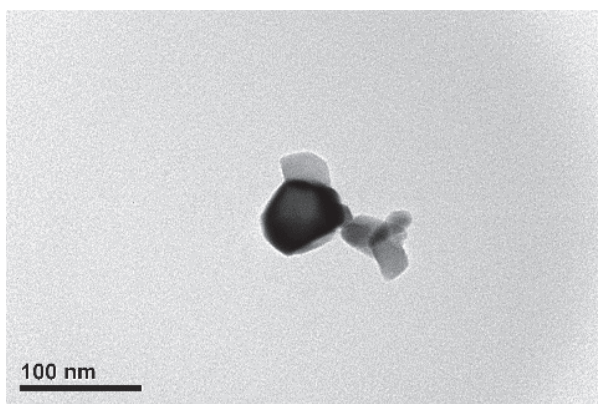

(a)

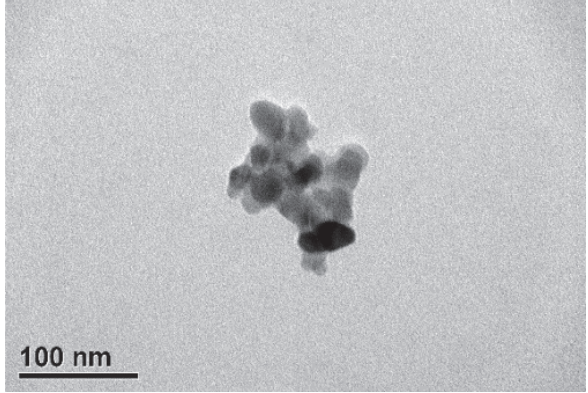

(b)

FIGURE 4: TEM images with scale bar of $100 \mathrm{~nm}$ for the morphology of $\mathrm{TiO}_{2}$ dispersed in de-ionic water with $5 \mathrm{wt} \%$ of (a) SHMP and (b) PAA stabilizers, respectively.

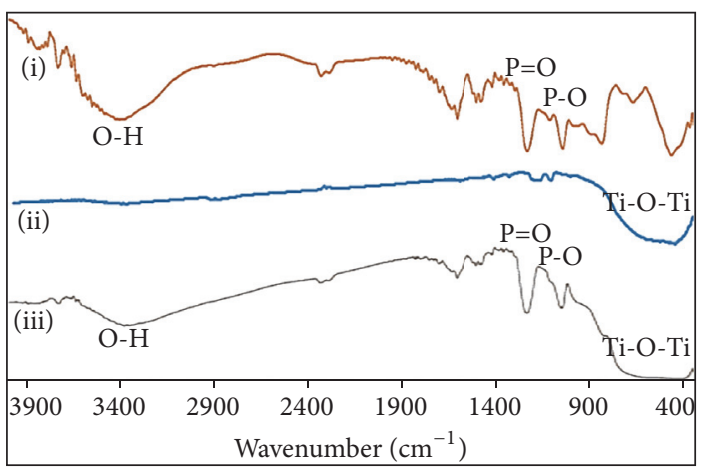

(a)

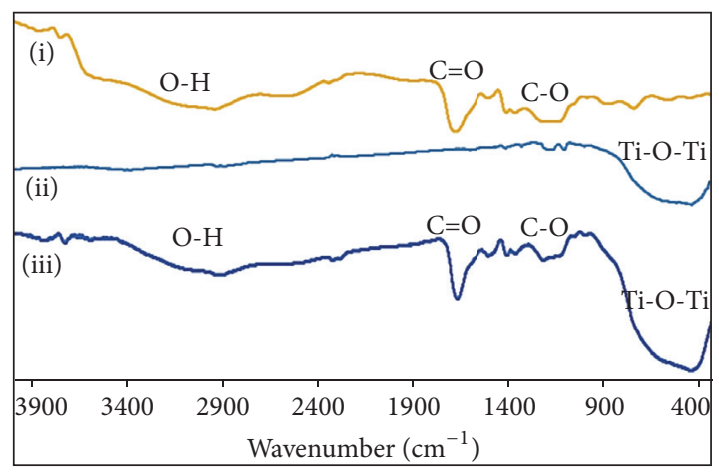

(b)

FIgURE 5: FTIR spectra of $\mathrm{TiO}_{2}$ particles after and before absorbing SHMP and PAA stabilizers, respectively, with (a-i) $\mathrm{SHMP}$ (a-iii) TiO ${ }_{2}^{-}$ SHMP; (b-i) PAA; (b-iii) $\mathrm{TiO}_{2}$-PAA; and (a-ii) and (b-ii) $\mathrm{TiO}_{2}$.

suspension without stabilizer as well as with SHMP and PAA. Additionally, both samples of SHMP and PAA achieved similar zeta potential values at $\mathrm{pH}$ values ranging from 7.7 to 10 , which may be induced by the extreme thickness of electrical double layer due to the limiting amount of stabilizer and that surface negative charge of dispersed $\mathrm{TiO}_{2}$ particle is increased by the $\mathrm{pH}$ value of suspension. In addition, without stabilizer, the zeta potential of $\mathrm{TiO}_{2}$ aqueous solution reaches $-40 \mathrm{mV}$, implying that the suspension is stabilized very well, which is in agreement with the previous reports [36,37], resulting from high polarity of surface in the high alkaline solution. Nevertheless, in the practical application, the $\mathrm{pH}$ value of suspension would be limited in the suitable range near to 7 for the operating safety. 


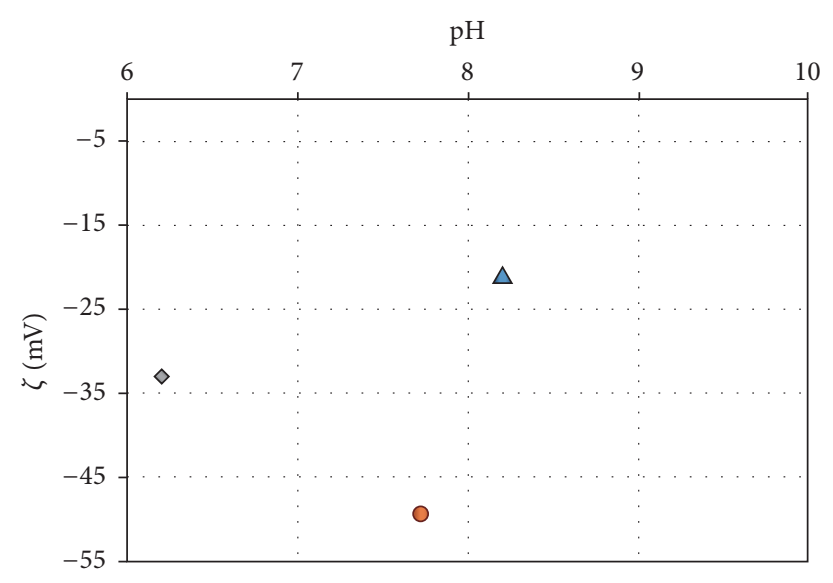

$$
\begin{aligned}
& \Delta \mathrm{TiO}_{2} \\
& \text { - } \mathrm{TiO}_{2} \text {-SHMP } \\
& \diamond \mathrm{TiO}_{2} \text {-PAA }
\end{aligned}
$$

FIGURE 6: Zeta potential of $\mathrm{TiO}_{2}$ suspension without stabilizer at $\mathrm{pH}$ value of 8.2, as well as with SHMP and PAA at pH values of 7.6 and 6.2 respectively.

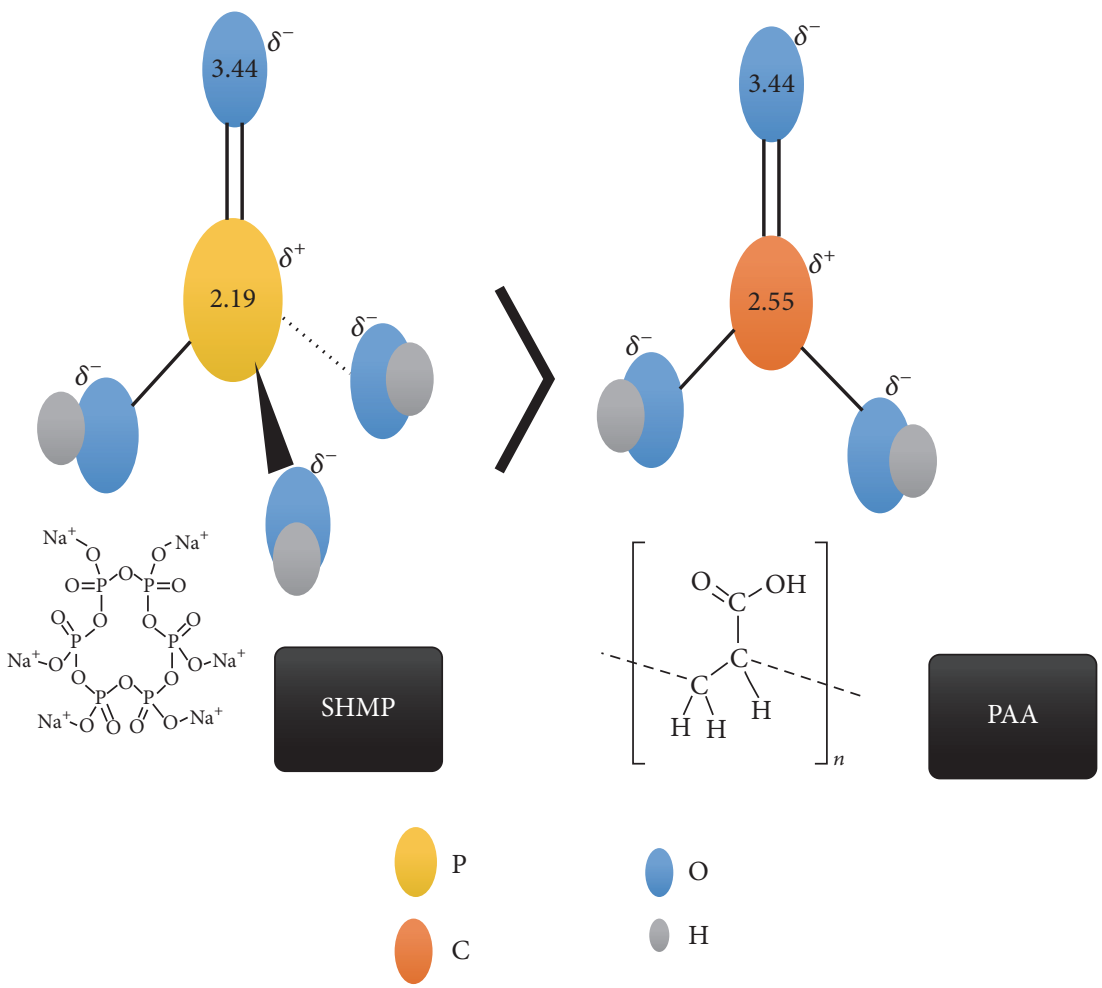

FIGURE 7: Sketch of polarity models and chemical structures of PAA and SHMP, respectively, where $\delta^{+}$and $\delta^{-}$express the positive and negative charges $[33,34]$, and the colors indicate the different atomics.

\section{Conclusion}

This study revealed that $\mathrm{TiO}_{2}$ nanoparticles were dispersed by ultrasonic wave combining with inorganic and organic stabilizers in aqueous solution. As shown in the results, we summarized the following remarks:
(1) The dispersion ability of SHMP was better than that of PAA due to the electronegativity of SHMP more than $\mathrm{PAA}$ in the $\mathrm{TiO}_{2}$ nanosuspension.

(2) The suitable amount of PAA and SHMP stabilizers could be determined by the variations of average 


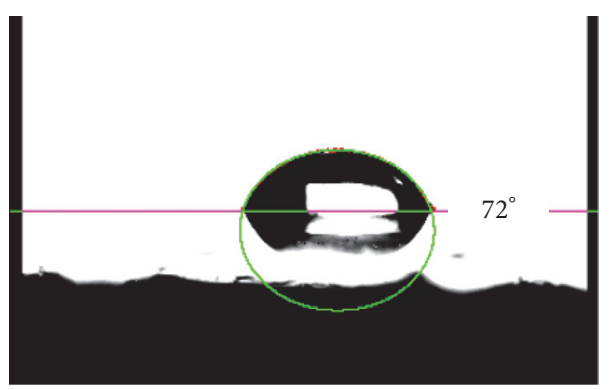

(a)

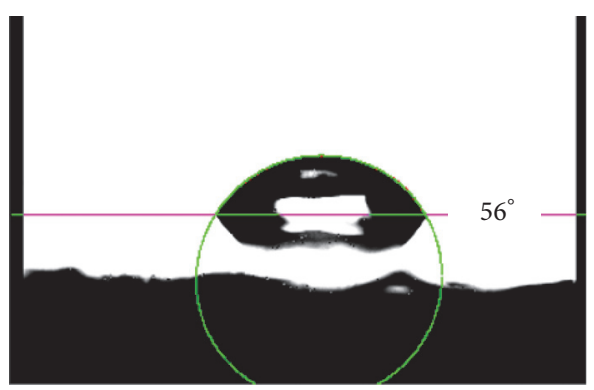

(b)

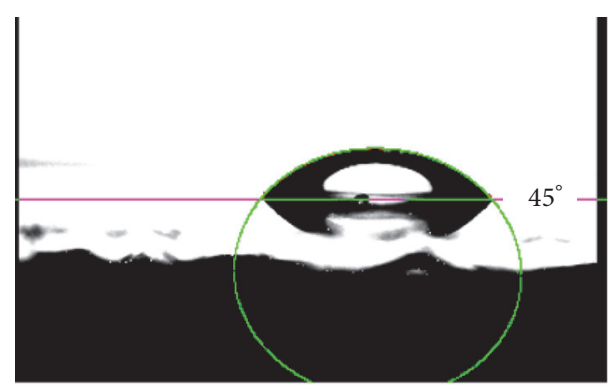

(c)

FIGURE 8: Surface contact angles of $\mathrm{TiO}_{2}$ suspension (a) without and with stabilizers of (b) SHMP and (c) PAA, respectively.

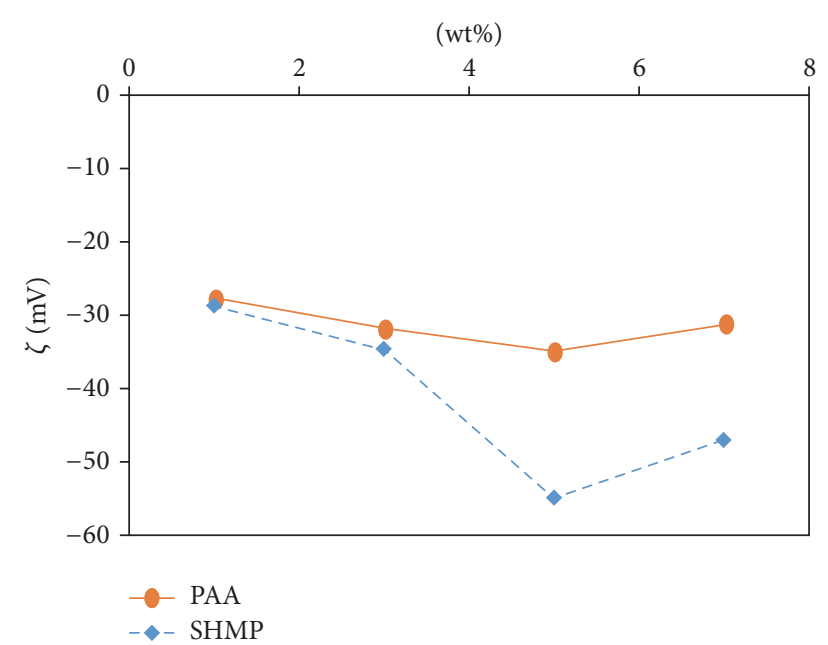

FIGURE 9: Zeta potential of dispersed $\mathrm{TiO}_{2}$ in de-ionic water varying with the amount of (a) SHMP (b) PAA stabilizers, respectively.

particle size and zeta potential with the amount of stabilizer to obtain maximum zeta potential of $\mathrm{TiO}_{2}$ nanosuspension.

(3) With $5 \mathrm{wt} \%$ of SHMP, the average particle size of dispersion solution containing $0.005 \mathrm{wt} \%$ of $\mathrm{TiO}_{2}$ particles was about $92 \mathrm{~nm}$ in de-ionic water, where zeta potential reaches $54 \mathrm{mV}$ at $\mathrm{pH}$ value of 7.7 .

Hopefully, these results could be expected to provide guidance to design nanofluid and functional coating with excellent performance.

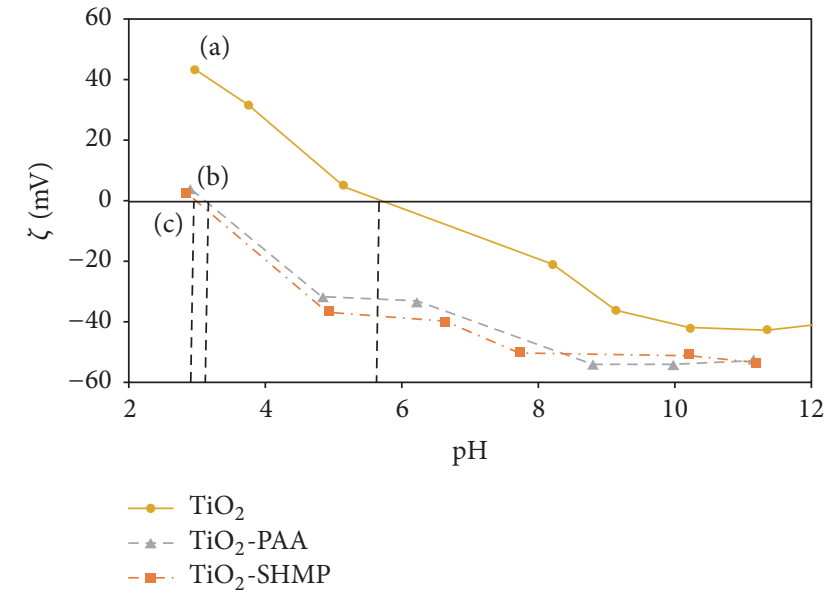

FIgURE 10: Zeta potential of $\mathrm{TiO}_{2}$ suspension with $5 \mathrm{wt} \%$ of (a) SHMP and PAA stabilizers, respectively, as functions of $\mathrm{pH}$ value.

\section{Competing Interests}

The authors declare that they have no competing interests.

\section{Acknowledgments}

The authors would like to deeply appreciate the financial support from Ministry of Science and Technology, Taiwan.

\section{References}

[1] J. O. Carneiro, V. Teixeira, A. Portinha et al., "Iron-doped photocatalytic $\mathrm{TiO}_{2}$ sputtered coatings on plastics for self-cleaning 
applications," Materials Science and Engineering B, vol. 138, no. 2, pp. 144-150, 2007.

[2] H. Lachheb, E. Puzenat, A. Houas et al., "Photocatalytic degradation of various types of dyes (Alizarin S, Crocein Orange G, Methyl Red, Congo Red, Methylene Blue) in water by UVirradiated titania," Applied Catalysis B: Environmental, vol. 39, no. 1, pp. 75-90, 2002.

[3] H. Zhang, H. Liu, C. Mu, C. Qiu, and D. Wu, "Antibacterial properties of nanometer $\mathrm{Fe}^{3+}-\mathrm{TiO}_{2}$ thin films," in Proceedings of the 1st IEEE International Conference on Nano Micro Engineered and Molecular Systems (NEMS '06), pp. 955-958, IEEE, Zhuhai, China, January 2006.

[4] H. Yu, K. Zhang, and C. Rossi, "Experimental study of the photocatalytic degradation of formaldehyde in indoor air using a nano-particulate titanium dioxide photocatalyst," Indoor and Built Environment, vol. 16, no. 6, pp. 529-537, 2007.

[5] L. Jin, H. Wu, and M. Morbidelli, "Synthesis of water-based dispersions of polymer/ $/ \mathrm{TiO}_{2}$ hybrid nanospheres," Nanomaterials, vol. 5, no. 3, pp. 1454-1468, 2015.

[6] J. Jiang, G. Oberdörster, and P. Biswas, "Characterization of size, surface charge, and agglomeration state of nanoparticle dispersions for toxicological studies," Journal of Nanoparticle Research, vol. 11, no. 1, pp. 77-89, 2009.

[7] D. H. Napper, Polymeric Stabilization of Colloidal Dispersions, Academic Press, Cambridge, Mass, USA, 1983.

[8] J. Hierrezuelo, A. Sadeghpour, I. Szilagyi, A. Vaccaro, and M. Borkovec, "Electrostatic stabilization of charged colloidal particles with adsorbed polyelectrolytes of opposite charge," Langmuir, vol. 26, no. 19, pp. 15109-15111, 2010.

[9] R. Greenwood and K. Kendall, "Selection of suitable dispersants for aqueous suspensions of zirconia and titania powders using acoustophoresis," Journal of the European Ceramic Society, vol. 19, no. 4, pp. 479-488, 1999.

[10] J. Cesarano III and I. A. Aksay, "Processing of highly concentrated aqueous $\alpha$-alumina suspensions stabilized with polyelectrolytes," Journal of the American Ceramic Society, vol. 71, no. 12, pp. 1062-1067, 1988.

[11] R. A. French, A. R. Jacobson, B. Kim, S. L. Isley, R. L. Penn, and P. C. Baveye, "Influence of ionic strength, $\mathrm{pH}$, and cation valence on aggregation kinetics of titanium dioxide nanoparticles," Environmental Science and Technology, vol. 43, no. 5, pp. 13541359, 2009.

[12] C.-C. Li, S.-J. Chang, and M.-Y. Tai, "Surface chemistry and dispersion property of $\mathrm{TiO}_{2}$ nanoparticles," Journal of the American Ceramic Society, vol. 93, no. 12, pp. 4008-4010, 2010.

[13] G. Li, L. Lv, H. Fan et al., "Effect of the agglomeration of $\mathrm{TiO}_{2}$ nanoparticles on their photocatalytic performance in the aqueous phase," Journal of Colloid and Interface Science, vol. 348, no. 2, pp. 342-347, 2010.

[14] E. De Giglio, S. Cometa, N. Cioffi, L. Torsi, and L. Sabbatini, "Analytical investigations of poly(acrylic acid) coatings electrodeposited on titanium-based implants: a versatile approach to biocompatibility enhancement," Analytical and Bioanalytical Chemistry, vol. 389, no. 7-8, pp. 2055-2063, 2007.

[15] Y. Tang, Y. Cao, S. Wang, G. Shen, and R. Yu, "Surface attached-poly(acrylic acid) network as nanoreactor to in-situ synthesize palladium nanoparticles for $\mathrm{H}_{2} \mathrm{O}_{2}$ sensing," Sensors and Actuators B: Chemical, vol. 137, no. 2, pp. 736-740, 2009.

[16] S. H. Othman, S. Abdul Rashid, T. I. Mohd Ghazi, and N. Abdullah, "Dispersion and stabilization of photocatalytic $\mathrm{TiO}_{2}$ nanoparticles in aqueous suspension for coatings applications," Journal of Nanomaterials, vol. 2012, Article ID 718214, 2012.
[17] S. Vallar, D. Houivet, J. El Fallah, D. Kervadec, and J.-M. Haussonne, "Oxide slurries stability and powders dispersion: optimization with zeta potential and rheological measurements," Journal of the European Ceramic Society, vol. 19, no. 6-7, pp. 1017-1021, 1999.

[18] S. Liufu, H. Xiao, and Y. Li, "Adsorption of poly(acrylic acid) onto the surface of titanium dioxide and the colloidal stability of aqueous suspension," Journal of Colloid and Interface Science, vol. 281, no. 1, pp. 155-163, 2005.

[19] Q. Rana, S. Wua, J. Shena, Q. Ranb, and J. Shenc, "Effects of poly(acrylic acid) on rheological and dispersion properties of aqueous $\mathrm{TiO}_{2}$ suspensions," Polymer-Plastics Technology and Engineering, vol. 46, no. 11, pp. 1117-1120, 2007.

[20] M. Vaara, "Agents that increase the permeability of the outer membrane," Microbiological Reviews, vol. 56, no. 3, pp. 395-411, 1992.

[21] H. C. Van der Mei, D. J. White, E. R. Cox, G. I. GeertsemaDoornbusch, and H. J. Busscher, "Bacterial detachment from salivary conditioning films by dentifrice supernates," Journal of Clinical Dentistry, vol. 13, no. 1, pp. 44-49, 2002.

[22] N. Khammar, L. Malhautier, V. Degrange, R. Lensi, and J.L. Fanlo, "Evaluation of dispersion methods for enumeration of microorganisms from peat and activated carbon biofilters treating volatile organic compounds," Chemosphere, vol. 54, no. 3, pp. 243-254, 2004.

[23] A. L. Cui, T. J. Wang, H. He, and Y. Jin, "Dispersion behavior of ultrafine titanium dioxide particles in aqueous solution," Cabinet Jacques Pezou Expertise, vol. 1, pp. 99-10, 2011.

[24] K. Sato, J.-G. Li, H. Kamiya, and T. Ishigaki, "Ultrasonic dispersion of $\mathrm{TiO}_{2}$ nanoparticles in aqueous suspension," Journal of the American Ceramic Society, vol. 91, no. 8, pp. 2481-2487, 2008.

[25] K. Higashitani, K. Yoshida, N. Tanise, and H. Murata, "Dispersion of coagulated colloids by ultrasonication," Colloids and Surfaces A: Physicochemical and Engineering Aspects, vol. 81, pp. 167-175, 1993.

[26] A. Ghadimi and I. H. Metselaar, "The influence of surfactant and ultrasonic processing on improvement of stability, thermal conductivity and viscosity of titania nanofluid," Experimental Thermal and Fluid Science, vol. 51, pp. 1-9, 2013.

[27] S. J. Chung, J. P. Leonard, I. Nettleship et al., "Characterization of $\mathrm{ZnO}$ nanoparticle suspension in water: effectiveness of ultrasonic dispersion," Powder Technology, vol. 194, no. 1-2, pp. 75-80, 2009.

[28] A. S. Alzaydien, "Physical, Chemical and Adsorptive Characteristics of Local Oak Sawdust Based Activated Carbons," Asian Journal of Scientific Research, vol. 9, no. 2, pp. 45-56, 2016.

[29] B. Erdem, R. A. Hunsicker, G. W. Simmons, E. David Sudol, V. L. Dimonie, and M. S. El-Aasser, "XPS and FTIR surface characterization of $\mathrm{TiO}_{2}$ particles used in polymer encapsulation," Langmuir, vol. 17, no. 9, pp. 2664-2669, 2001.

[30] C. R. Mayer, S. Neveu, F. Secheresse, and V. Cabuil, "Supramolecular assemblies of gold nanoparticles induced by hydrogen bond interactions," Journal of Colloid and Interface Science, vol. 273, no. 2, pp. 350-355, 2004.

[31] H. Bala, W. Fu, J. Zhao et al., "Preparation of $\mathrm{BaSO}_{4}$ nanoparticles with self-dispersing properties," Colloids and Surfaces A: Physicochemical and Engineering Aspects, vol. 252, no. 2-3, pp. 129-134, 2005.

[32] H. Karimian and A. A. Babaluo, "Halos mechanism in stabilizing of colloidal suspensions: nanoparticle weight fraction and 
pH effects," Journal of the European Ceramic Society, vol. 27, no. 1, pp. 19-25, 2007.

[33] A. L. Allred, "Electronegativity values from thermochemical data," Journal of Inorganic and Nuclear Chemistry, vol. 17, no. 3-4, pp. 215-221, 1961.

[34] W. B. Jensen, "Electronegativity from avogadro to pauling: part 1: origins of the electronegativity concept," Journal of Chemical Education, vol. 73, no. 1, pp. 11-20, 1996.

[35] J. Duplat, S. Kheifets, T. Li, M. G. Raizen, and E. Villermaux, "Superdiffusive trajectories in Brownian motion," Physical Review E, vol. 87, no. 2, Article ID 020105, 2013.

[36] J. M. Berg, A. Romoser, N. Banerjee, R. Zebda, and C. M. Sayes, "The relationship between $\mathrm{pH}$ and zeta potential of $\sim 30$ $\mathrm{nm}$ metal oxide nanoparticle suspensions relevant to in vitro toxicological evaluations," Nanotoxicology, vol. 3, no. 4, pp. 276283, 2009.

[37] C. Sentein, B. Guizard, S. Giraud, C. Yé, and F. Ténégal, "Dispersion and stability of $\mathrm{TiO} 2$ nanoparticles synthesized by laser pyrolysis in aqueous suspensions," Journal of Physics: Conference Series, vol. 170, Article ID 012013, 2009. 

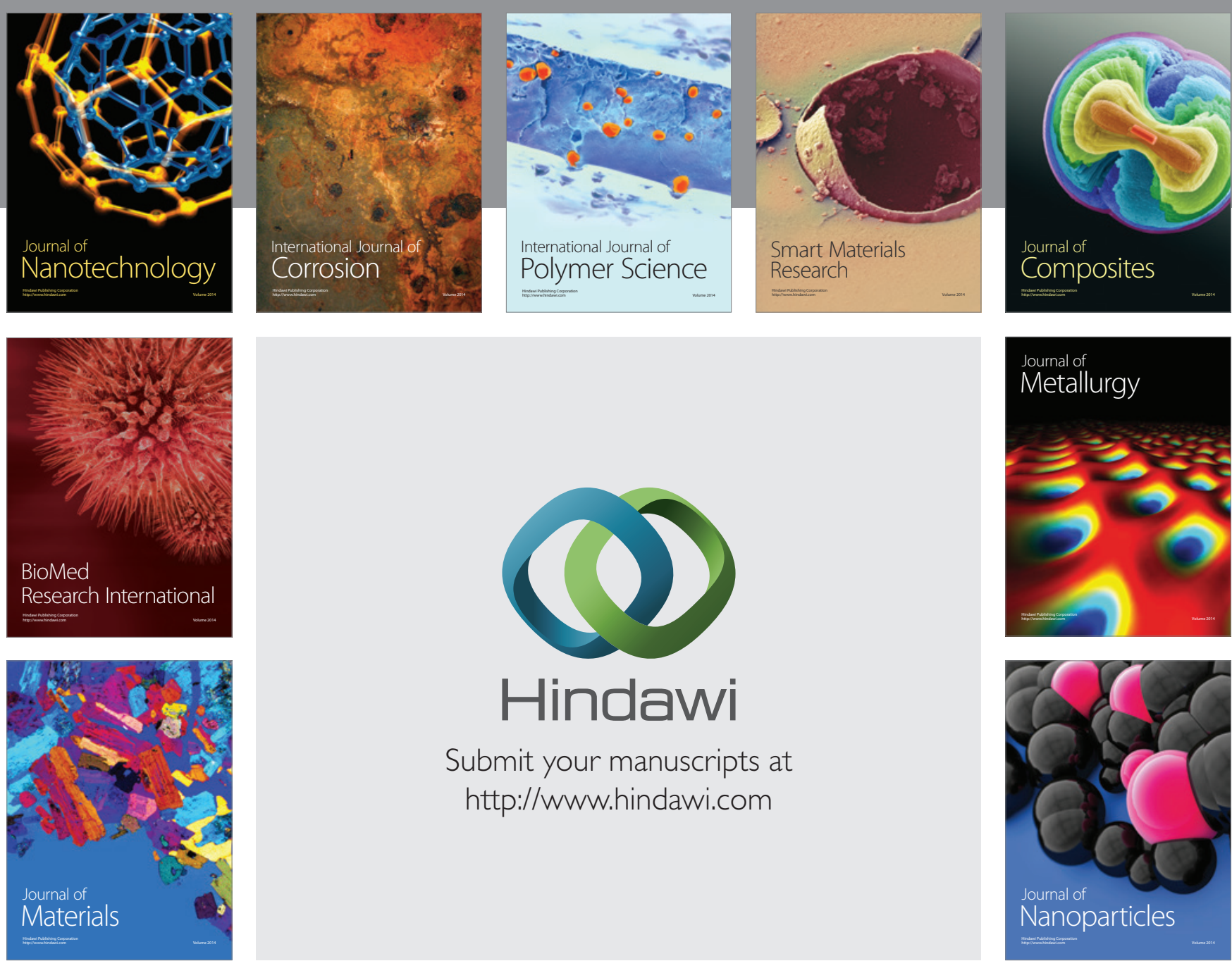

\section{Hindawi}

Submit your manuscripts at

http://www.hindawi.com

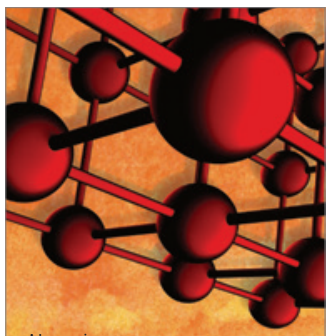

Materials Science and Engineering
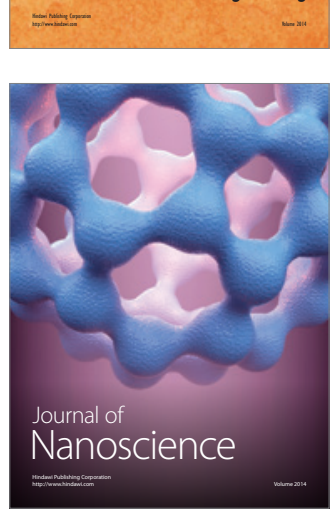
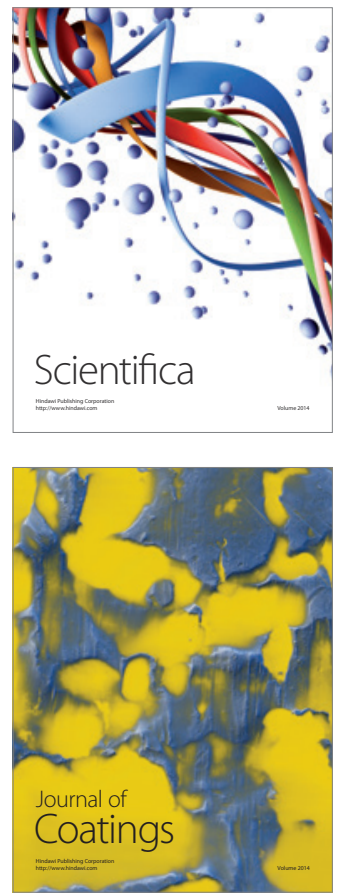
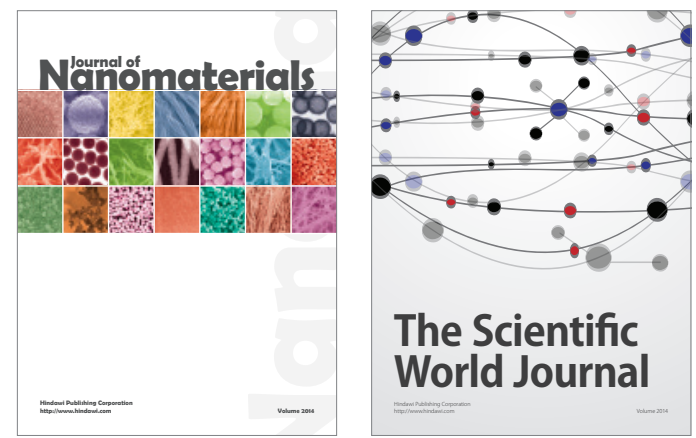

The Scientific World Journal
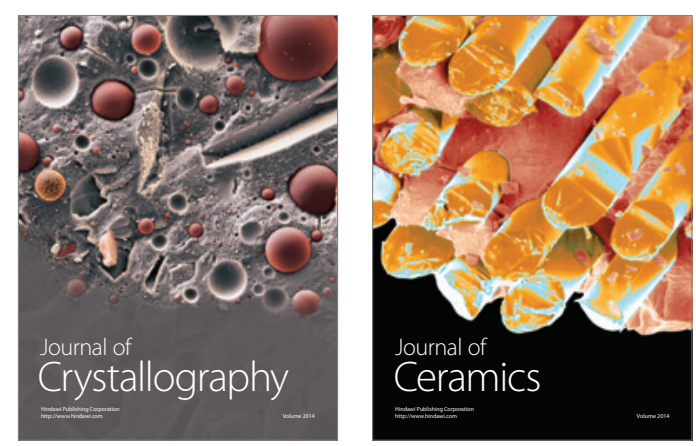
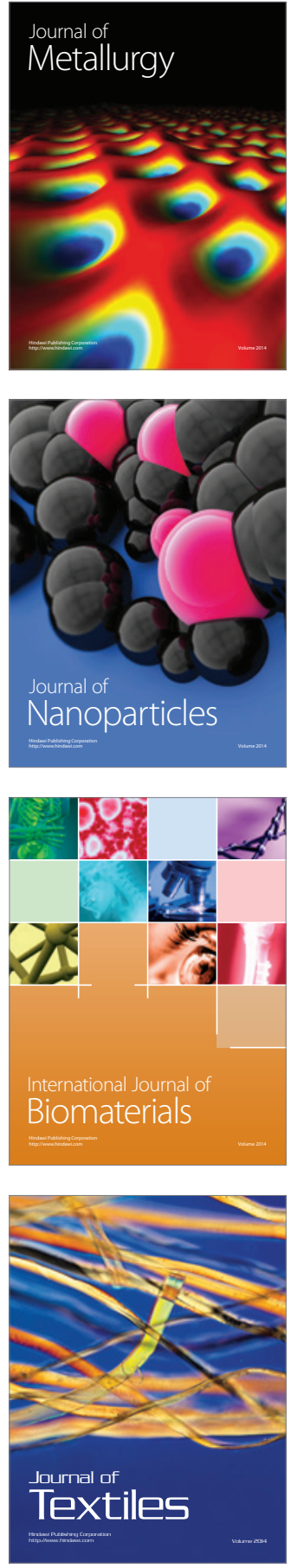